Article

\title{
Development of a More Descriptive Particle Breakage Probability Model
}

\author{
Murray M. Bwalya ${ }^{1}$ (1) and Ngonidzashe Chimwani ${ }^{2, *}$ \\ 1 School of Chemical and Metallurgical Engineering, University of the Witwatersrand, Johannesburg 2050, \\ South Africa; mulenga.bwalya@wits.ac.za \\ 2 Institute of the Development of Energy for African Sustainability (IDEAS), a Research Centre of the \\ University of South Africa (UNISA), Florida Campus, Private Bag X6, Johannesburg 1710, South Africa \\ * Correspondence: ngodzazw@gmail.com; Tel.: +27-731838174
}

Received: 8 June 2020; Accepted: 6 August 2020; Published: 12 August 2020

\begin{abstract}
Single-particle breakage test is becoming increasingly popular, as researchers seek to understand fracture response that is purely a function of the material being tested, instead of that which is based on the performance of the comminution device being used. To that end, an empirical breakage probability model that builds on previous work was proposed. The experimental results demonstrate the significance of both energy input and the number of repeated breakage attempts. Four different materials were compared, to gain a better insight into the breakage response. This modelling work goes further from previous research of the authors, by showing that not only does size related threshold energy and repeated impacts characterize particle breakage properties, but each material exhibits unique trends in terms of how its threshold energy and its rate of deterioration varies with particle size and each impact, respectively. This behaviour can be attributed to the different mechanical characteristics of the material and their flaw distribution. The importance of these aspects was highlighted.
\end{abstract}

Keywords: single particle breakage; energy input; drop-weight tester; breakage modelling; grinding prediction

\section{Introduction}

For quite some time, researchers have been pursuing an understanding of particle fracture at a fundamental level. This approach is necessary, as it would help in the design of equipment that achieves the most desirable outcomes. There has been appreciable progress to some extent, however, in most cases, the understanding is more focused on the equipment comminuting the particles. The JKMRC introduced a single breakage test equipment to establish a way of separating material breakage properties from the influence of equipment. This, however, introduces the challenge of relating material breakage response data obtained independent of the target comminution device to the performance to be expected. Thus, as Delboni and Morell [1] point out, the identification of the mechanisms involved in comminution equipment is imperative for the successful modelling of its comminution process.

In the 19th century, Rittinger [2] and Kick [3] proposed some comminution energy laws; Kick proposed comminution energy to be a function of the volumetric reduction ratio, while Rittinger related it to the new surface area produced. It was however not possible based on these laws to predict how much energy would be required to achieve a particular level of size reduction. Reasonable success has somewhat been achieved by Bond's energy law [4], which was suggested to be based on Griffith's law of crack propagation [5].

The theory proposed by Griffith's highlighted the importance of pre-existing flaws within particles. Using this theory, energy balance around the crack could be calculated and energy required to extend 
the crack and consequently produce a new surface could be thus determined. It will just be mentioned in passing that, while grinding is directed towards forming new surface area, most of the energy invested in the process is absorbed by other aspects unrelated to comminution, as Rumpf [6] observed. This somewhat complicates the problem of relating input energy to the resulting product. In addition, no two particles will have an identical distribution of inherent cracks, and thus some statistical modelling of these tests is inevitable. It should also be pointed out that the tests must be representative of the stressing mechanism, that is to be expected in the comminution device being targeted by the test; otherwise, there would be little correlation between the test and the actual equipment performance.

The JKMRC initially introduced the pendulum test and refined the technique, by developing the drop-weight tester $[7,8]$. Further enhancement of the test procedure has been made by the introduction of the JK rotary breakage tester [9], which has reduced the time required for testing significantly, though this test now relies more on a single impact than double impact.

Bwalya et al. [10] explored a modified equation of Weichert [11], and applied it to drop-weight test breakage data. This model went further by recognizing repeated breakage attempts as being equally important as energy input in determining the probability of particle breakage. This was the first time this factor was included, and this has since then appeared in later models [12-14]. The tests were done on some specific material, which led to a successful demonstration of how this could be combined with the discrete element method (DEM) energy spectral output to predict milling rates of grinding processes. The model was described by this equation:

$$
P_{b}=1-e^{-(0.006 m+5) n^{0.525}\left(\frac{E-E_{x 0}}{E_{x 0}}\right)}
$$

where $P_{b}$ is the probability of breaking a particle of mass $m$ in grams, and every particle which lost $25 \%$ or more by volume to daughter fragments due to breakage was recorded as broken $n$ and $E(J)$ are number of impact attempts and energy input level, respectively. $E_{x_{0}}(\mathrm{~J})$ (particle threshold energy) is the minimum energy level required to initiate any form of breakage in a particle. This is derived by plotting energy levels against the probability of breakage; the point where the extrapolated curve crosses the x-axis is assumed to be the $E_{x_{0}}$ value.

To illustrate this method, a graph after Bwalya [15] is shown in Figure 1, and an example of the application of this same technique based on present work is presented in Figure A1. Surprisingly, the $E_{x 0}$ value for any particle size for the gold waste-rock was described accurately by the equation:

$$
E_{x 0}=0.19 m^{0.76}
$$

where $m$ is the mass in grams.

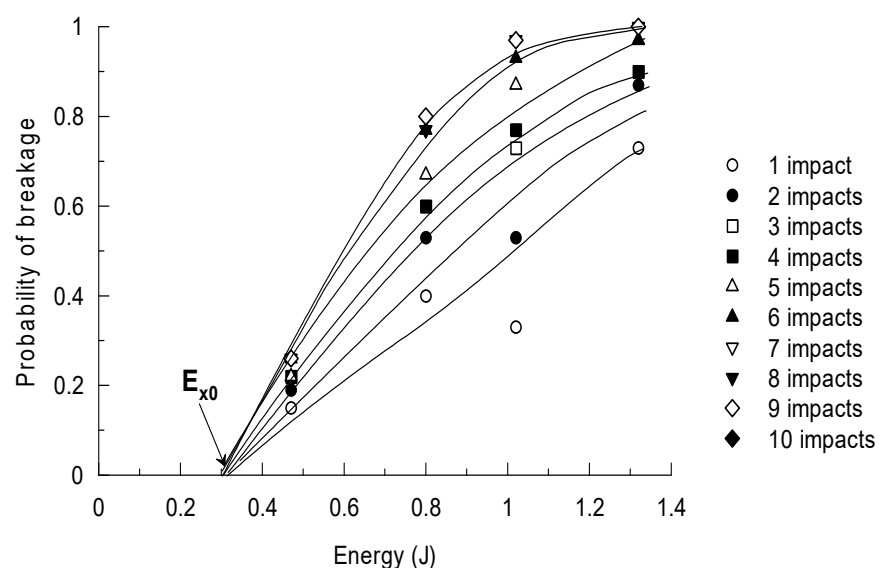

Figure 1. Determination of $E_{x 0}$ (minimum energy required for fracture) after [15]. 
The main feature that emerged from that work is that both input energy level and number of impact attempts significantly affect the probability of breakage. The higher the energy input level, the faster the breakage probability approaches the asymptotical maximum value of 1 with each repeated impact. With a lower energy input level, the breakage probability slope increase is much slower, thus, requires several more impact attempts to reach the value of 1 . These characteristics are illustrated in Figure 2, after Bwalya and Moys [16]. While it is impressive that the probability of breakage can be well correlated with drop-weight test data, there is uncertainty with the determination of the energy that is actually used up in breakage.

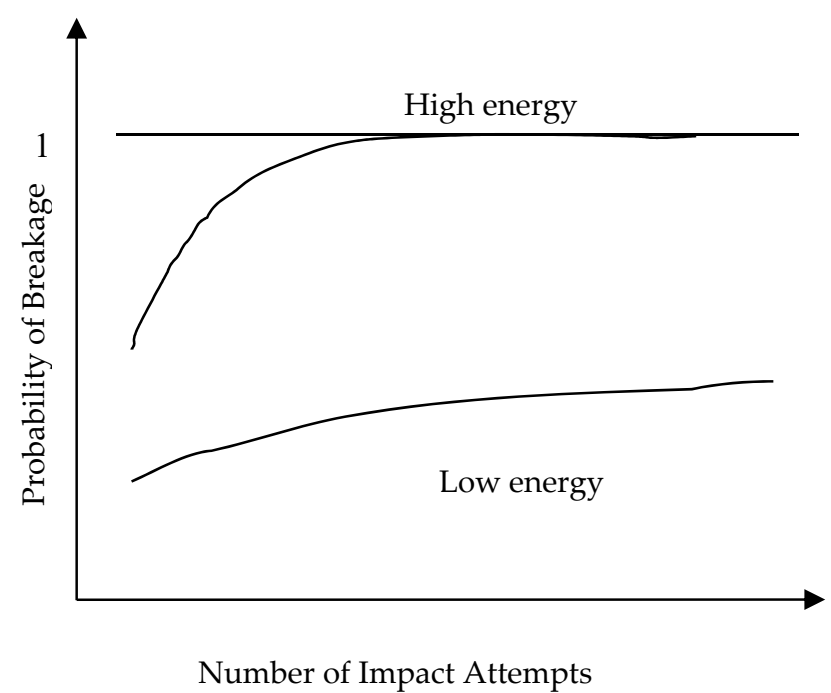

Figure 2. The influence of energy input and breakage attempts required to break a particle.

The ultra-fast load cell (UFLC) that has been developed at The University of Utah [17], has the advantage of capturing the fracture events at high resolution. A force-time profile is recorded during the contact event between impactor and particle, which is used to accurately calculate the energy input to the point of fracture. The force-time profile can also be used to study other events, such as secondary fracture, and for this reason, it has been a leading tool in characterizing single particle breakage with great detail $[18,19]$.

Though the major goal of this research is to develop a scheme for using DEM to predict grinding rate in ball mills, the present work is limited to adequately modelling particle breakage response to varying levels of input energy and repeated stress application in drop weight tests. As observed by Genc et al. [20], the drop weight tester has the advantages of being more flexible and generally yielding consistent results. A good overview of the current status of drop weight testing was given by Shi [21]; Chandramohan et al. [22]; Hosseinzadeh and Ergun [23], whilst quantitative descriptions of breakage probability by repeated impacts were proposed by Bonfils et al. [24]; Tavares and King [25]. Shi's [21] review demonstrates how the adaptation of Equation (1) to the prediction of the breakage function has been successfully applied by the JKMRC to model numerous industrial cases.

The researchers cited above generally recognize the significance of both size related threshold energy, as well as cumulative impact effect. In this work, a modelling approach is developed that allows independent variation of both size related threshold energy and damage deterioration phenomenon, to cater for a wider range of materials. It remains to be seen if this approach will be able to correlate with material structure and flaws distribution.

To model particle breakage response to successive impacts, three key factors are considered:

- Threshold energy

- Rate of deterioration with each impact

- Energy relationship with size 
The concept of rate of deterioration is based on the assumption that, for particles of the same material and same size, the resistance to breakage is supposed to be the same, and the only explanation for variation is that some will have larger existing flaws, causing them to break at earliest attempts. For some materials, to extend these flaws only requires a few impact attempts, while for other materials, crack growth with successive impacts will be slower. Plastic deformation may also, to some extent, contribute to the overall process that leads to eventual particle failure.

Figure 2 shows a typical increase in the probability of breakage as a function of impact energy, and Equation (2) shows how particle size relates with threshold energy. An explicit equation that builds on Equations (1) and (2) has been developed, which is written as follows:

$$
P_{b}=1-\exp \left(-a n^{b}\left(\frac{E-c m^{d}}{c m^{d}}\right)\right)
$$

where $a$ and $b$ are parameters modelling deterioration with each impact, $c$ and $d$ model how threshold energy varies with particle size. Moreover, $m$ as defined before is the particle mass in grams. An inquiry is thus made in this research to determine if the developed model can successfully establish the relationship between impact energy and the particle breakage and show how the threshold energy varies with particle size. A programme of experimental work on different materials is presented in a subsequent section to test this model.

\section{Materials and Methods}

This section contains a general procedure that was used for preparing the three different materials (silica sandstone, dolomite and low-grade coal sample) that were tested. A fourth material (gold waste rock) is considered from Bwalya's thesis [15] where a similar procedure was used. The crushed material was reduced to test size, using either rotary sampler or Riffler, and graded to different sizes using screens with a fourth root screen ratio limitation between the upper and lower screen. Each mass group comprised 150 particles, which were then subdivided into three groups of 50 particles. Figure 3 shows the schematic of the preparation steps. Table 1 gives the size classes that were prepared.

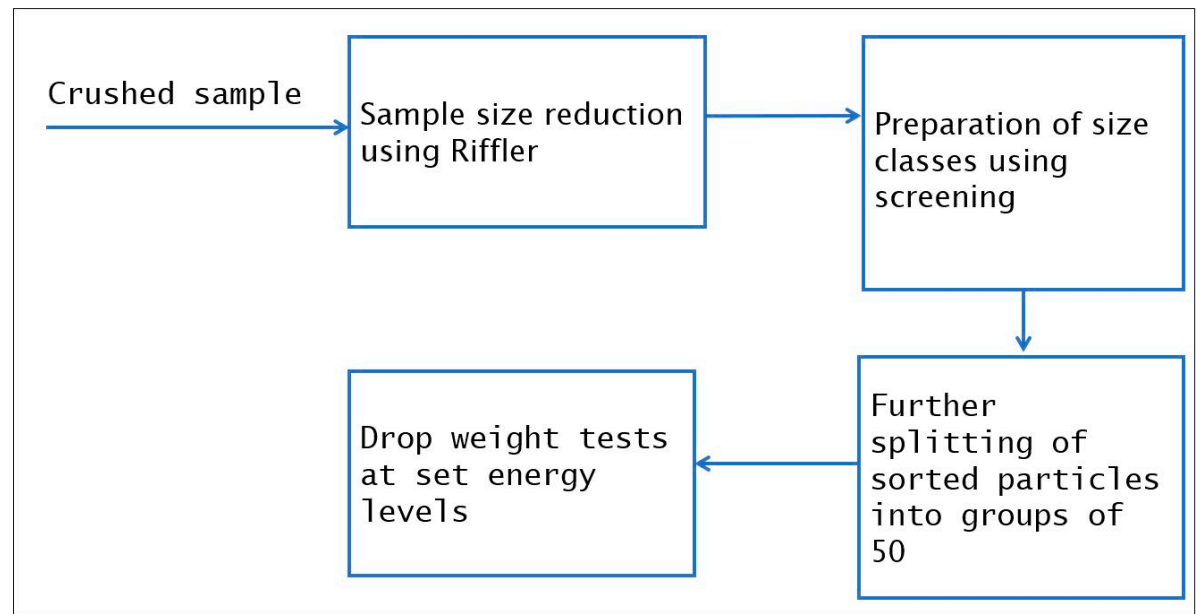

Figure 3. Sample preparation steps.

Table 1. Size classes used of the different material used for drop weight tests.

\begin{tabular}{|c|c|c|}
\hline Material & Size Class in mm & Approximate Density $\left(\mathrm{g} / \mathrm{cm}^{3}\right)$ \\
\hline Silica Sandstone & $-26.5+22.4,-19+16,-11.2+9.5$ & 2.65 \\
\hline Dolomite & $-31.5+26.5,-26.5+22.4,-19+16,-11.2+9.5$ & 2.84 \\
\hline Low-Grade Coal & $-31.5+26.5,-26.5+22.4,-19+16,-11.2+9.5$ & 1.7 \\
\hline Gold Waste Rock & $\begin{array}{c}-75+63,-45+37.5,-37.5+31.5,-19+16,-16+ \\
13.2,-13.2+11.2,-11.2+9.5\end{array}$ & 2.75 \\
\hline
\end{tabular}


The particle groups were then subjected to breakage tests, particle by particle, in an in house- built drop weight tester manufactured in the Chemical and Metallurgical Engineering Department at the University of Witwatersrand (Johannesburg, South Africa). This is illustrated in Figure 4. Since apart from density, particle shape is another important criterion that affects average mass of material retained on a screen, Figure 5 is included to show the samples of material used, the size ranges of which are specified in Table 1.

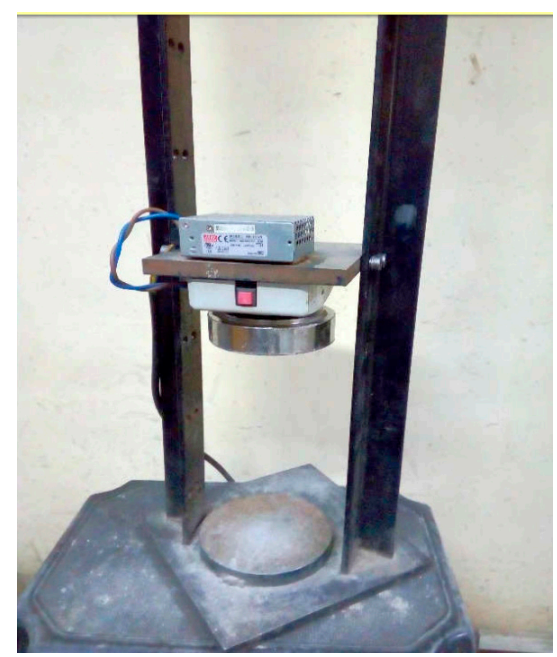

(a)

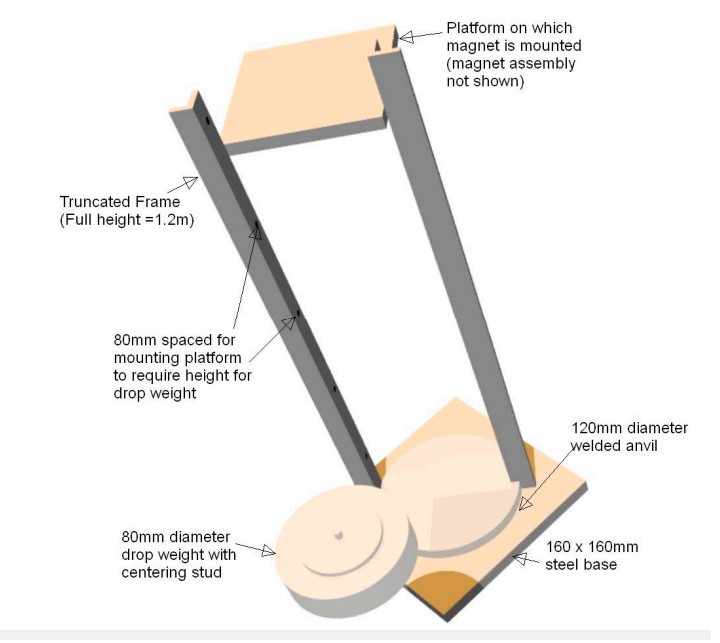

(b)

Figure 4. (a) Picture of the drop weight tester, (b) with illustration to highlight its main features.

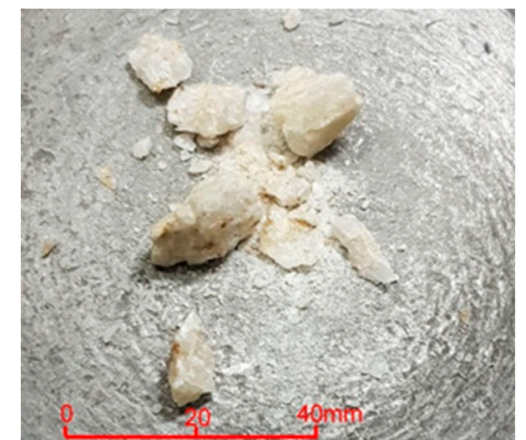

Silica sandstone

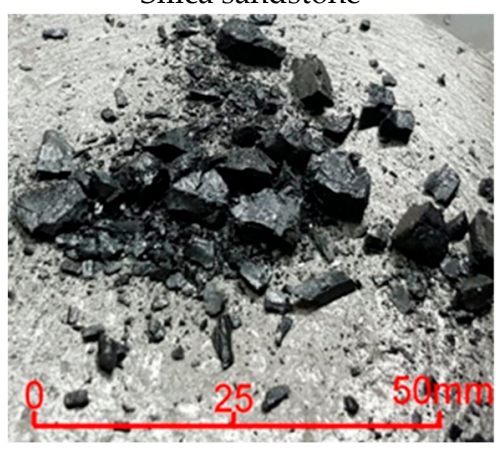

Low-grade coal

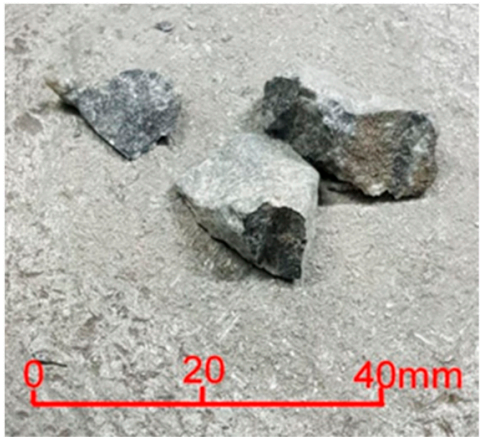

Dolomite

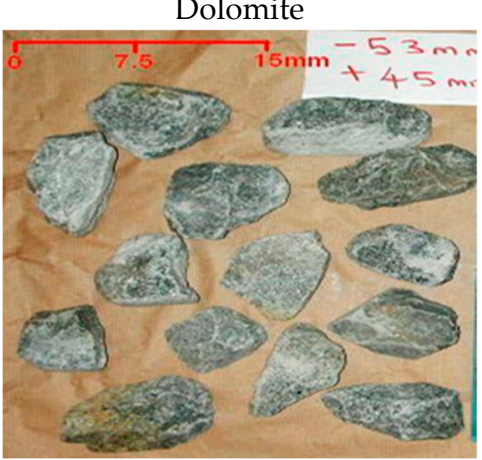

Gold waste rock

Figure 5. Display of the samples of material used in the drop weight tests.

For each particular sub-group, the energy input was varied between 0.63 and $4.4 \mathrm{~J}$ by altering the mass of the weight and its drop height. The two steel disc weights used weighed $1.6 \mathrm{~kg}$ and $3.07 \mathrm{~kg}$. Energy input was controlled by varying the drop height between 0.1 and $1.2 \mathrm{~m}$, in steps of $0.08 \mathrm{~m}$. 
These steps correspond to the position of holes in the vertical steel frame that allow the platform holding the magnet to be positioned flexibly, and tightened by pins.

To each of the particle groups prepared for the test, one breakage attempt was made on each particle, and every particle which lost $25 \%$ or more by volume to daughter fragments due to breakage was recorded as broken, as mentioned in the previous section. Those that survived were subjected to another impact and the number of broken particles at the second attempt was recorded once again. The maximum number of repeated attempts was pegged at 5 . Upon completion of the test for a particular group, the resulting fragments from all the particles were combined and sieve analysed to determine the size distribution of the fragments, which will be the topic of a future publication by the authors.

The energy level would then be changed by adjusting the drop height or the drop weight and the procedure repeated for the next group of 50 particles. Thus, each mass group had a low, medium and high energy input level from which a breakage probability table was compiled (see Table 2 as an example). Input energy for any particle was calculated using Equation (4):

$$
E=M g\left(h_{1}-h_{2}\right)
$$

where $M$ is the steel weight mass $(\mathrm{kg}), g$ is the gravitational acceleration, and $h_{1}$ is the height above the platform where the drop weight is mounted. Moreover, $h_{2}$ is the final rest height after breakage, and this is dependent on the residue fragment size distribution.

Table 2. Parameters obtained for the different materials.

\begin{tabular}{ccccc}
\hline Parameters & Silica & Dolomite & Low-Grade Coal & Gold Waste Rock \\
\hline c & 0.03 & 0.33 & 0.07 & 0.19 \\
d & 0.99 & 0.37 & 0.42 & 0.72 \\
a & 0.12 & 0.34 & 0.23 & 0.41 \\
b & 0.83 & 0.70 & 0.50 & 0.52 \\
\hline
\end{tabular}

\section{Results}

The probability of breakage was varied with energy input level, as well as impact attempts for one particular particle size group. It was observed that with a low energy input level of $0.65 \mathrm{~J}$, only $18 \%$ of the particles were broken at first attempt, and with the second attempt, a further $13 \%$ was broken, bringing the cumulative total to $31 \%$. It was also observed that at the end of the 5 th attempt, only $53 \%$ of the particles are broken. These results are represented by the lowest experimental data points in Figure 6.

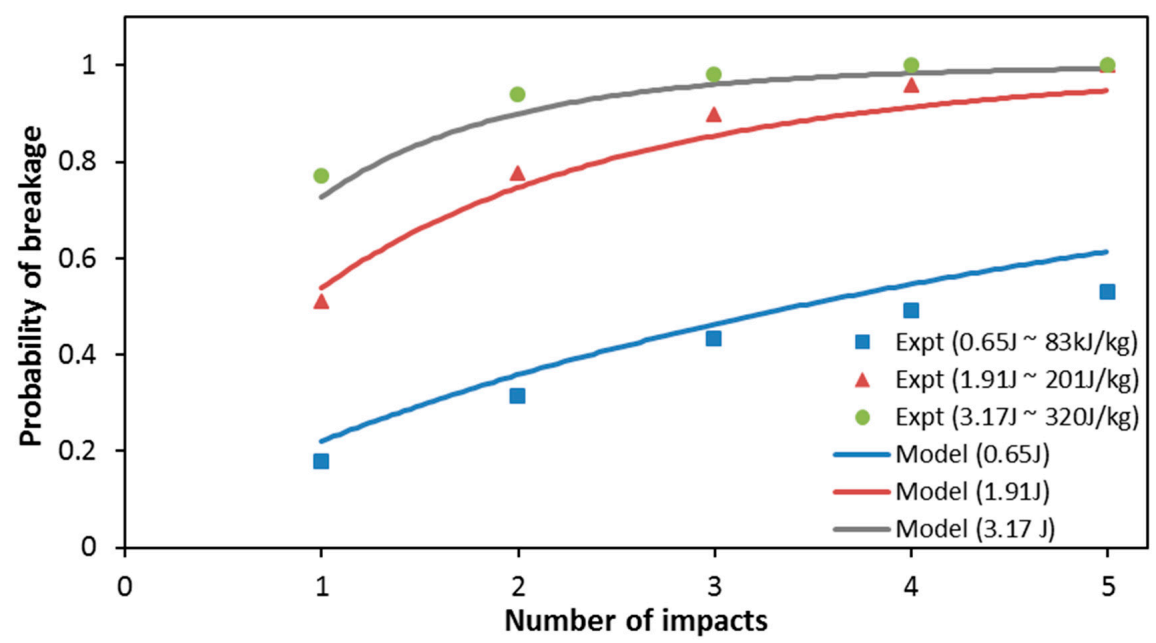

Figure 6. Comparison of experiment breakage probabilities with the model prediction for the $-19+$ $16.0 \mathrm{~mm}$ silica particles. 
It was seen that, when higher energy levels are used, the probability of breakage increases accordingly. With the energy level of $3.17 \mathrm{~J}$, all particles were broken within 3 attempts, as can be seen for the highest experimental data points in Figure 6. This trend was also observed in Figure 7 and is typical of all the other size groups, albeit with correspondingly higher energy input levels used for bigger particles.

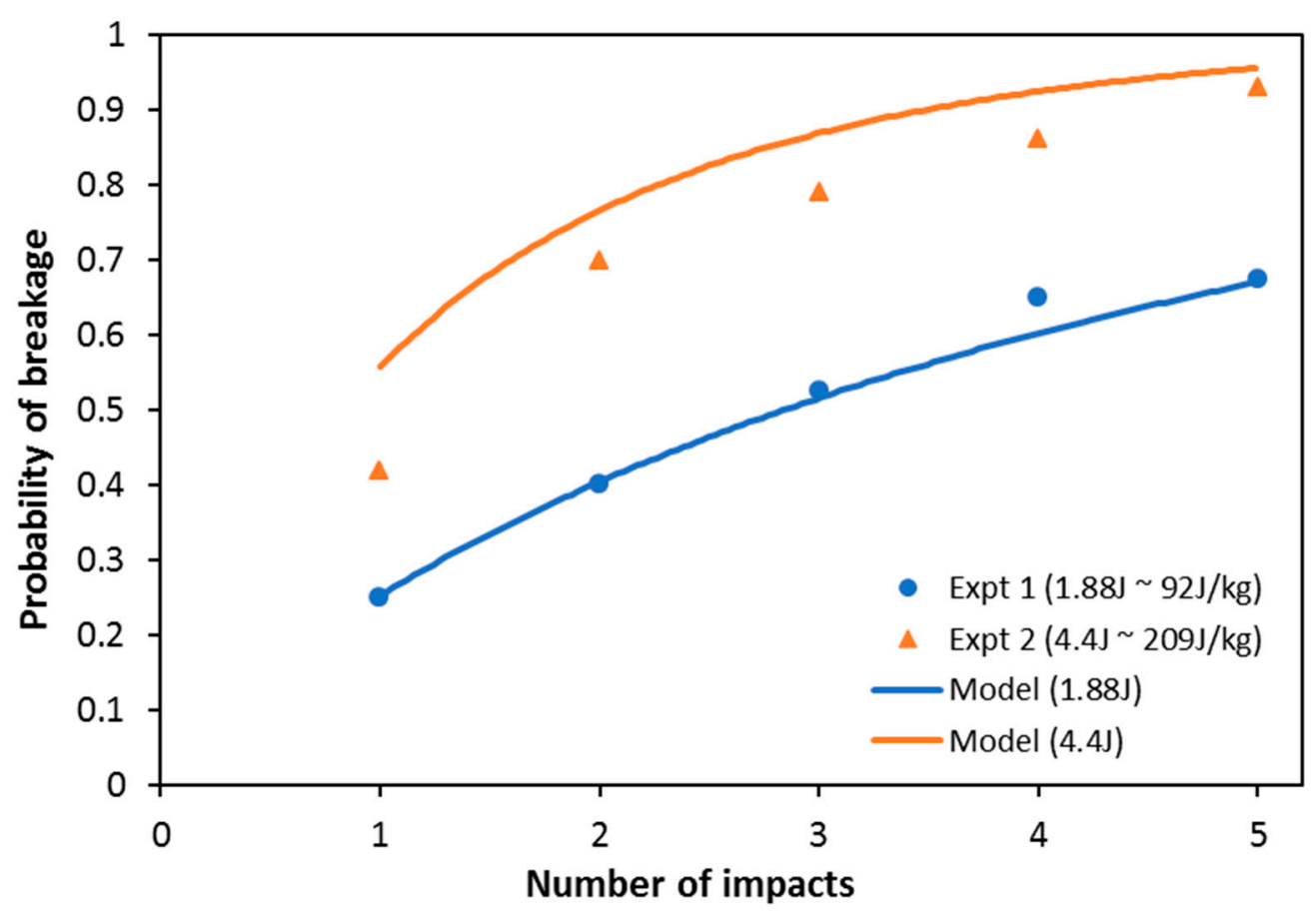

Figure 7. Comparison of experiment breakage probabilities with the model prediction for the $-26.5+$ $22.4 \mathrm{~mm}$ silica particles.

The trends of breakage probability increasing with both magnitude of energy input and number of successive breakage attempts described in the foregoing paragraphs are similar for the different size groups. Similar trends were also observed for the different materials, as can be seen in Figures 8-10 plotted in the next section. The only difference being the magnitudes of energy input responsible for those effects.

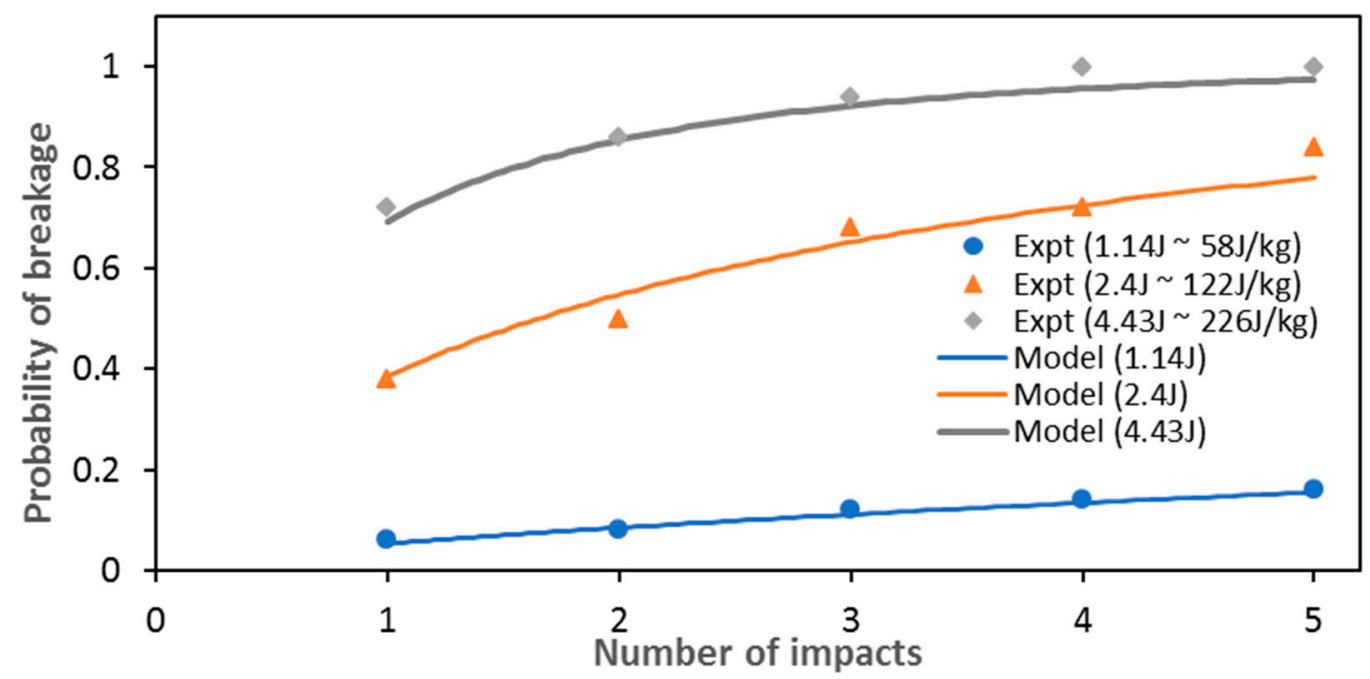

Figure 8. Experimental and Model Breakage probability curves for a $-26.5+22.4 \mathrm{~mm}$ Dolomite sample. 


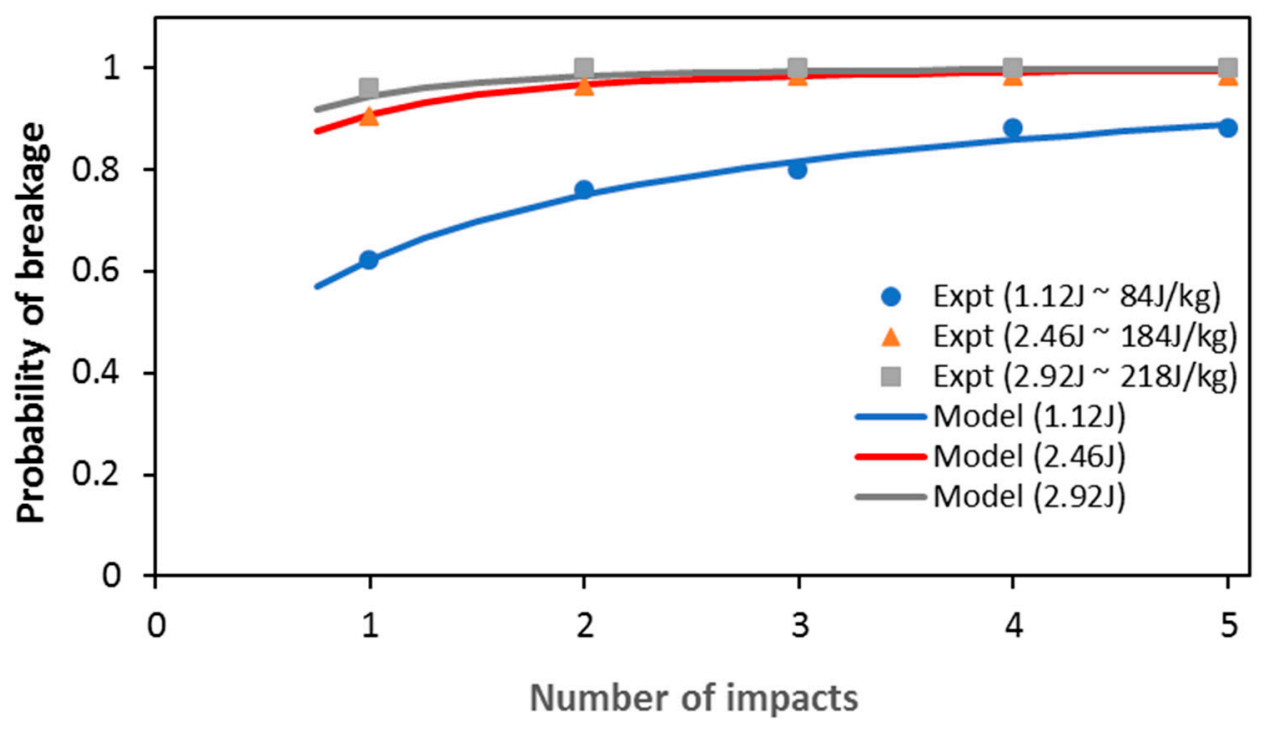

Figure 9. Experimental and Model Breakage probability curves for a $-26.5+22.4 \mathrm{~mm}$ Coal sample.

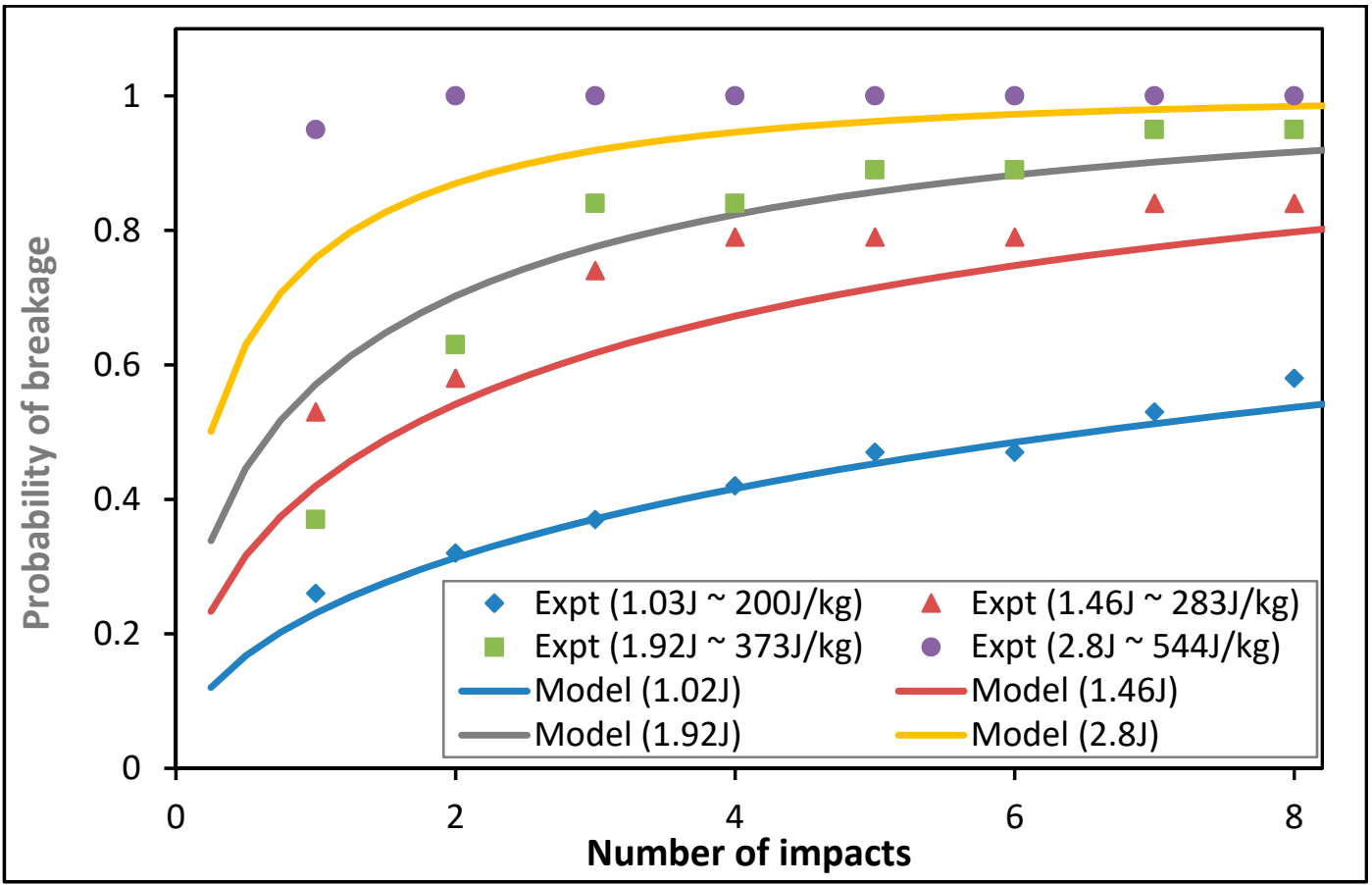

Figure 10. Experimental and Model Breakage probability curves for a $-16 \mathrm{~mm}+13.2 \mathrm{~mm}$ Gold waste rock sample.

\subsection{Modelling Results}

The model parameters presented in Table 2 were obtained for the four different materials, using the least sum of squares of the differences between model and the experimental values. The Excel Solver add-in was activated to iterate using the general reduced gradient non-linear routine, to find a solution that minimised the differences between the experimental and predicted data. The results for all the materials that were tested are presented in Figures 6-10 and the parameter values, compiled for these different materials, are presented in Table 2.

Figures 6 and 7 show how the model, to a great extent, has successfully described the Silica breakage data for the two sizes shown. It is clearly seen that though the graphs are similar, it is not easy to tell if for similar specific energy input per kilogram; one size class breaks more easily than the other. It will be shown later that for some materials, the specific energy $(\mathrm{J} / \mathrm{kg})$ required for breakage is 
size indifferent, while for most materials, smaller particles require more energy relatively, to achieve similar breakage.

Using appropriate material parameters, it was seen that the model also described these other data very well. The same size range for both the dolomite and coal samples was selected to facilitate comparison among the three materials.

Though the energy inputs do not correspond exactly, it is evident that coal is the weakest material. The gold waste rock sample is definitely the toughest of the lot, as its smaller particles exhibits similar resistance to breakage as other samples under similar impact loading. As can be seen in Figure 10, its specific energy input is higher than the other materials. A more in-depth analysis is carried out in the next section.

\subsection{Discussion}

\subsubsection{Effect of Size on Particle Strength}

To appreciate the significance of threshold energy, size normalised $E_{x 0}$ was plotted in Figure 11 and it was observed that generally the materials get weaker with increasing particle size. Most researchers attribute this to an increase in flaw density with increase in particle size. Apparently, it is not the case with the silica, which has the same threshold energy for the entire size range.

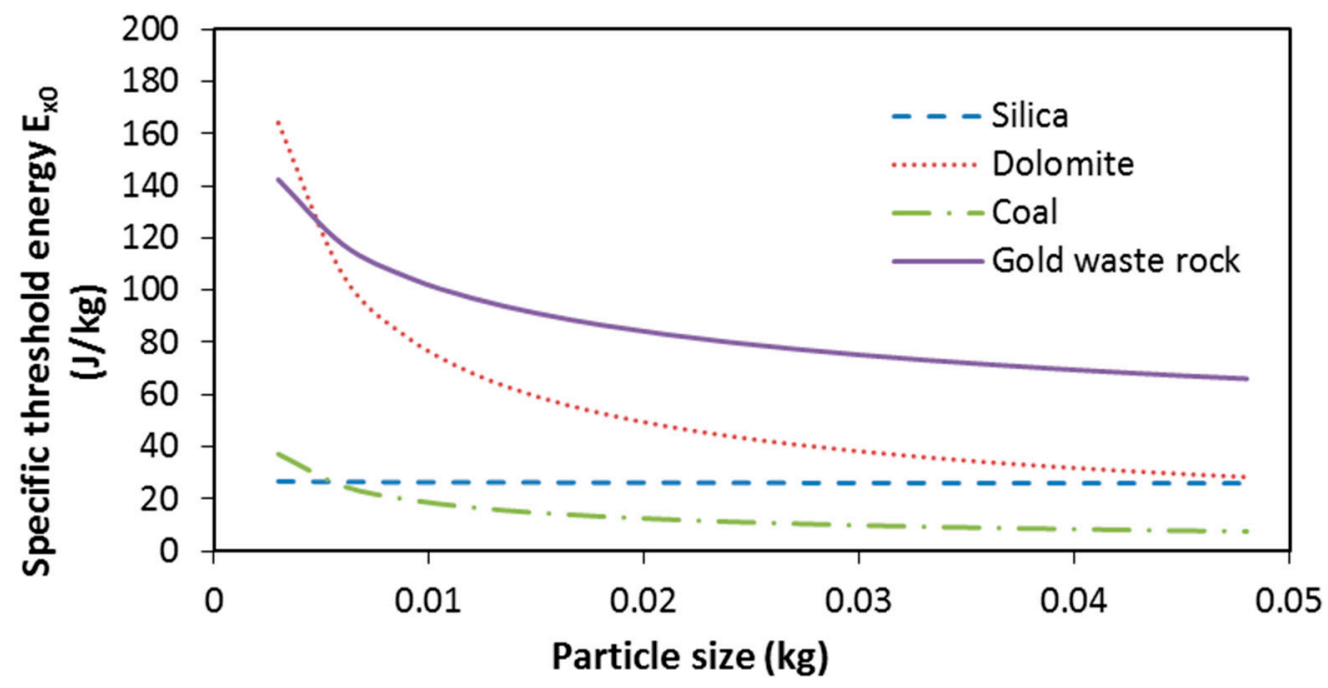

Figure 11. Comparison of specific threshold energy (J/kg).

It was observed for the coal that the increase in relative strength with size was gradual. Extrapolation of the model suggests that this starts to increase exponentially as particles become smaller than $10 \mathrm{~g}$. As for the gold waste rock and the dolomite, the relative increase in toughness with decreasing particle size is at a much higher rate. To show the implication of this phenomenon, specific probability breakage results for both gold waste rock and silica were compared.

In Figure 12, breakage probabilities at similar specific energy input are compared for the gold waste rock for $-13.2+11.2 \mathrm{~mm}$ and $-19+16 \mathrm{~mm}$ particles; it is seen clearly that the breakage probabilities for similar specific energy input are higher for the coarser particles. In other words, the bigger particles are relatively weaker for this material [26]. In Figure 13, a similar comparison is made for silica material for the $-26.5+22.4 \mathrm{~mm}$ and $-19+16 \mathrm{~mm}$ particles, and it is seen that the breakage probability differences for similar specific energy input are not as drastic as those seen for the gold waste rock in Figure 12. Apparently, the smaller particles offered stronger resistance to breakage at low energy input while at higher energy input, they were broken relatively more easily. 


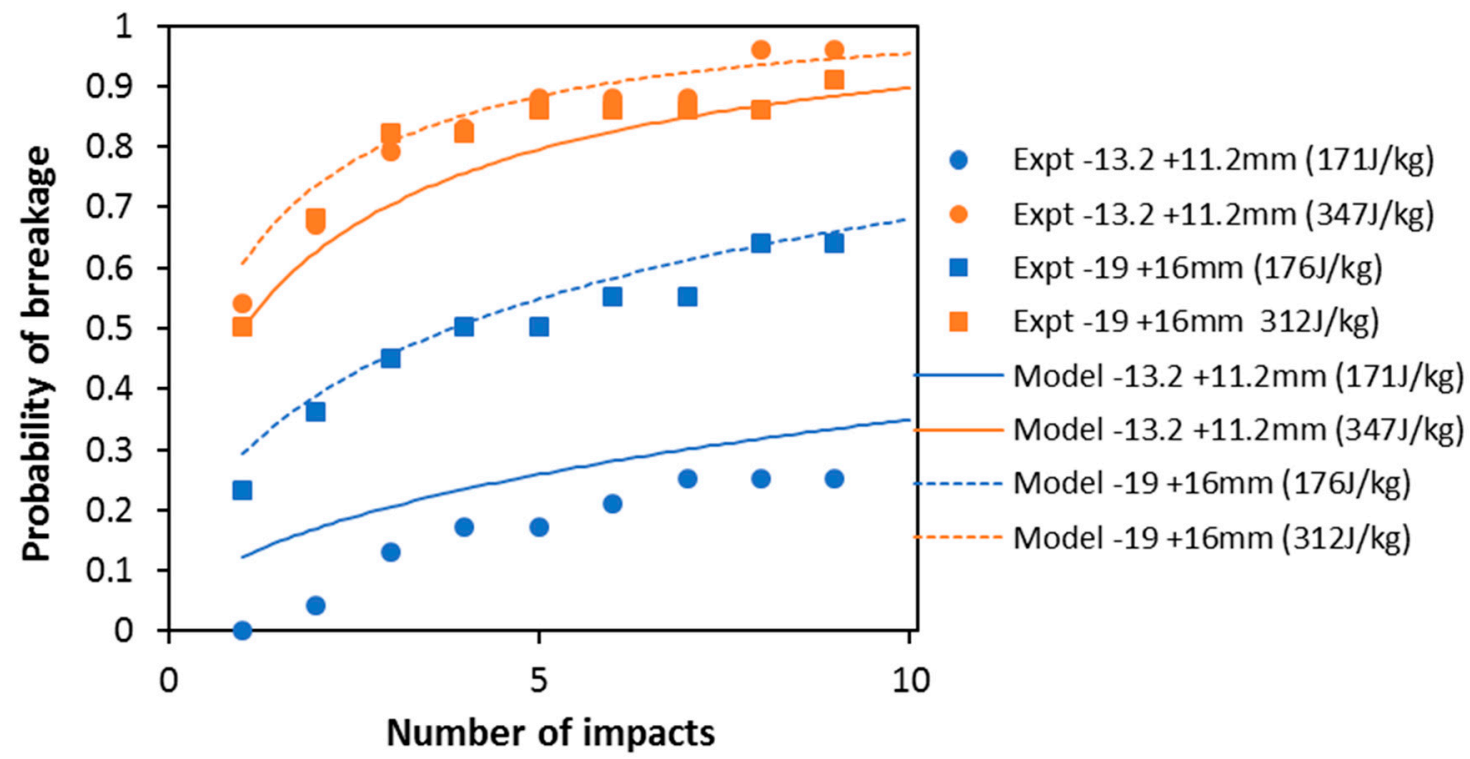

Figure 12. Comparison of gold waste rock breakage probabilities for two particle sizes at specific impact energy input.

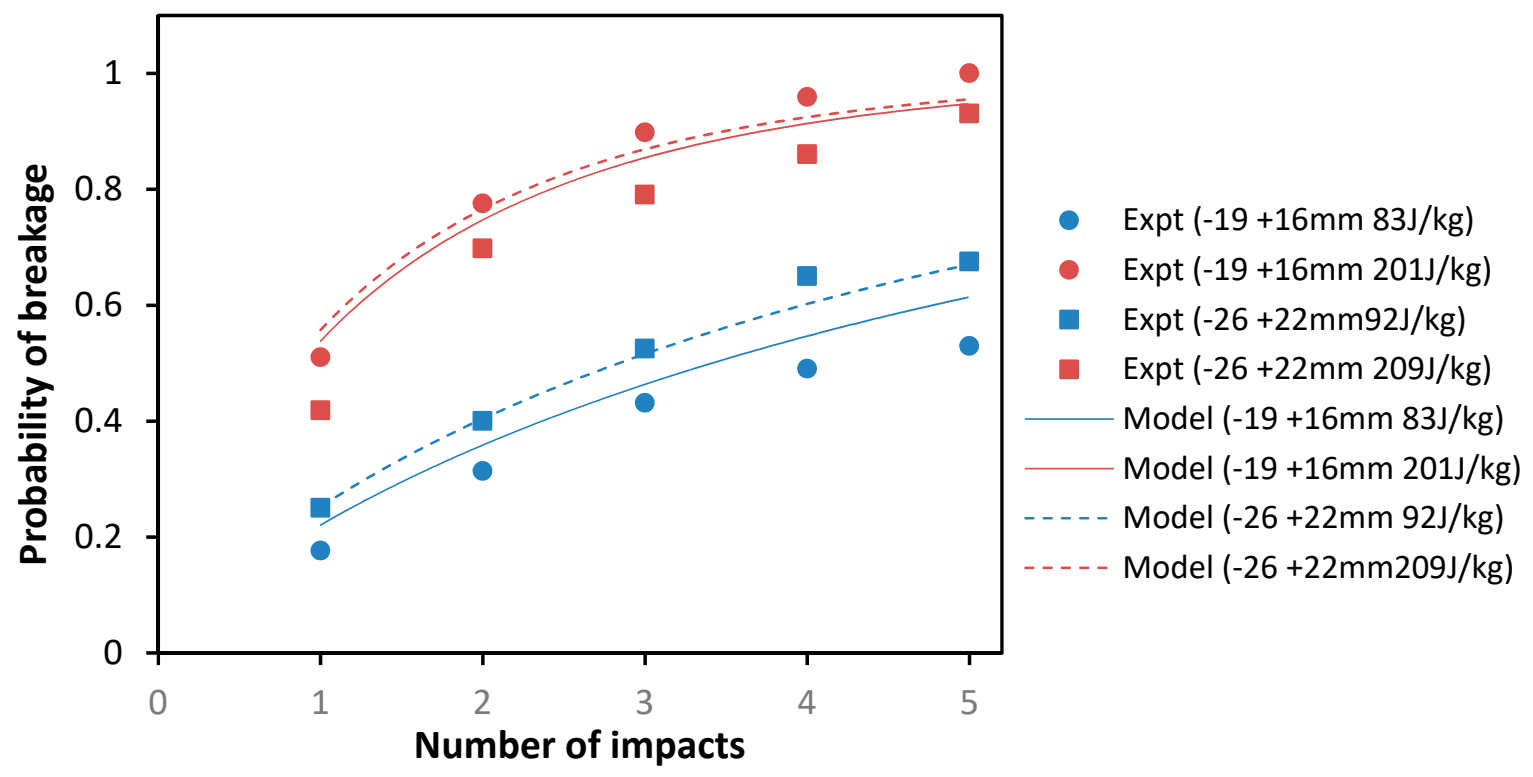

Figure 13. Comparison of silica breakage probabilities at similar specific impact energy input.

\subsubsection{Difference in Damage Accumulation in Materials}

The rate of deterioration with each impact can also be compared by normalising the part comprising energy terms in Equation (3) to get the following equation:

$$
P_{b}=1-e^{\left(-a n^{b}\right)}
$$

when parameters $a$ and $b$ are applied to this equation for the different materials, the result is what is seen in Figure 14. This reveals some interesting aspects about the materials; with the exception of silica, the other materials appear to become more difficult to break. Here, the silica stands out due to its brittle nature; it is seen that as long as the threshold energy is exceeded, each impact causes significant cumulative damage. However, it was noticed that, for both the coal and gold waste rock, the relative damage is minimal with each impact. This difference may probably be due to non-brittle deformation 
behaviour or the tendency of some materials to plastically deform, thus requiring further breakage attempts before yielding.

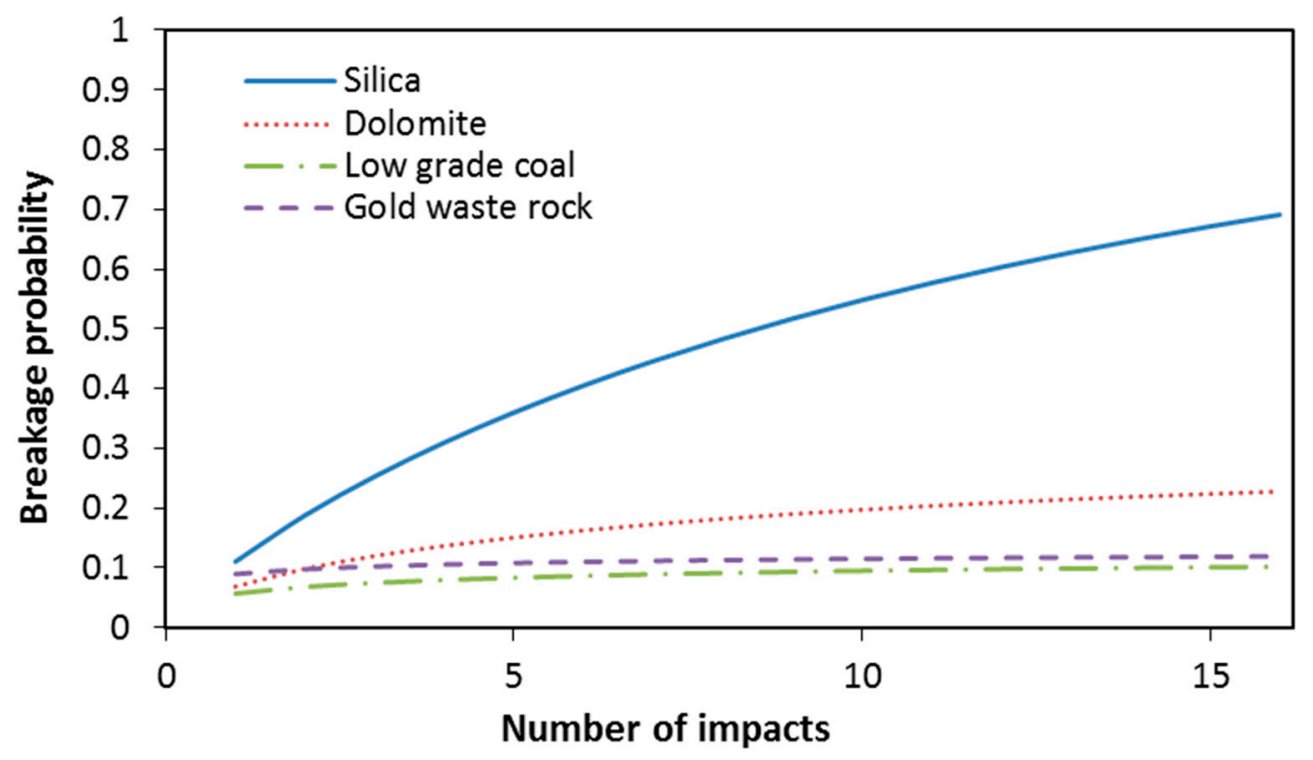

Figure 14. Comparison of the rate of deterioration with each impact for different materials.

It is natural to assume that a high $E_{x 0}$ value would usually indicate that a particular material is difficult to break, but as demonstrated above, $E_{x 0}$ varies differently for some materials, and one material which is stronger at a smaller size can end up being stronger at a different size. It was also observed that a material with a low $E_{x 0}$ can still be difficult to break if it has a low rate of deterioration with successive impacts. As such, it is recommended to test particles contained in various size ranges, to capture the observed size effect.

The model described by Equation (3) was also tested against published data from Morrison et al. [14]; using the Excel solver to estimate model parameters, the model successfully described the data. Thus, there is a good indication that this model could be of wide applicability, and future tests on more different types of material are planned.

In Appendix B is included Figure A2, which presents an algorithm that has been proposed by Bwalya [15] that applies breakage probability data to DEM simulation to predict the comminution rate in size reduction equipment.

\section{Conclusions}

The fracture response of particles to energy input is dependent on the material types and flaw size and density, which varies with particle size. This has been the basis of most of the probability fracture models that have been developed recently. The new model has demonstrated that it is possible to characterize particle breakage properties from the size related threshold energy point of view. The model has revealed that materials exhibit unique trends in terms of how their threshold energy and rate of deterioration vary with particle size and each impact, respectively. Its ability to predict particle fracture probability has also been successfully demonstrated on four different materials. Among the materials tested, gold waste rock proved to be the toughest, and its relative increase in toughness with decreasing particle size was also higher than the other three materials. The difference in cumulative damage beyond the threshold energy may be attributed to non-brittle deformation behaviour or plastic deformation of particles. The purely brittle material will require a few impacts to disintegrate, while those with plastic deformation tendencies will endure several more impacts before complete failure. As for the differences in threshold energies, the existence of flaws which are relatively bigger and more frequent in larger particles was considered to be a key factor. The damage accumulation 
as a result of repeated impacts is likely a function of properties such as the shape, composition, flaw distribution, and the presence of mineral grains, whose effects will be the object of future research by the authors.

Author Contributions: Conceptualization, M.M.B. and N.C.; methodology, M.M.B. and N.C.; software, M.M.B.; validation, M.M.B. and N.C.; formal analysis, M.M.B. and N.C.; investigation, M.M.B. and N.C.; resources, M.M.B. and N.C.; data curation, M.M.B. and N.C.; writing-original draft preparation, M.M.B. and N.C.; writing-review and editing, M.M.B. and N.C.; visualization, M.M.B. and N.C; supervision, M.M.B. and N.C.; project administration, M.M.B. and N.C.; funding acquisition, Y.Y. All authors have read and agreed to the published version of the manuscript.

Funding: This research received no external funding.

Acknowledgments: MINTEK is greatly acknowledged for allowing the authors to use the drop weight tester and their laboratory facility. The authors particularly mention Portai Mudau for ensuring that all their needs were met during the time of experiments.

Conflicts of Interest: The authors declare no conflict of interest.

\section{Nomenclature}

a dimensionless material parameter that is related to material resistance to damage

$b \quad$ dimensionless material parameter that is related to material brittleness

c parameter that models particle size effect on breakage

$d$ second parameter that models particle size effect on breakage

E energy (J)

$E_{x 0} \quad$ minimum energy $(\mathrm{J})$ required to initiate any form of particle damage

$g \quad$ gravitational acceleration $\left(\mathrm{m} / \mathrm{s}^{2}\right)$

$h \quad$ height (m) applies to all subscripts

M mass $(\mathrm{kg})$

$n \quad$ number of breakage attempts made on a particle

$P_{b} \quad$ probability of breaking a particle (in our case by at least $20 \%$ )

$X \quad$ particle mass $(\mathrm{g})$

$X_{m} \quad$ particle mass $(\mathrm{kg})$

\section{Appendix A}

Determination of $E_{x 0}$ applied to the dolomite sample.

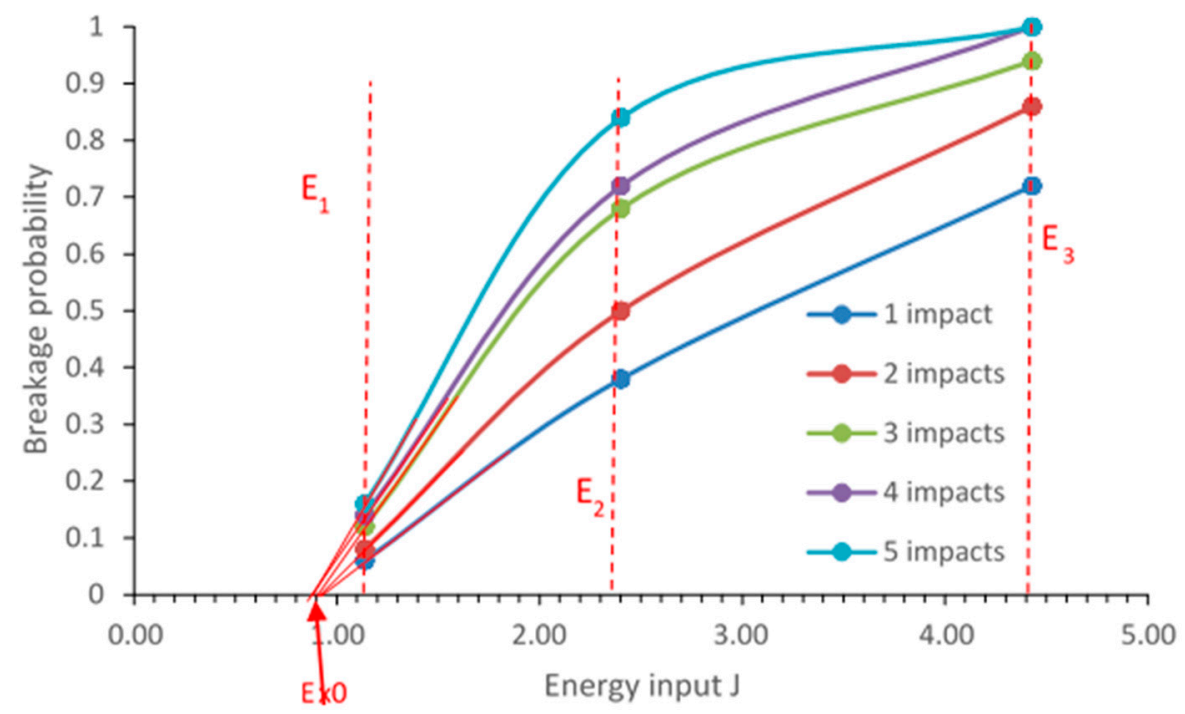

Figure A1. Determination of $E_{x 0}$ applied to the dolomite sample.

It is important to note that the lowest energy level $\left(E_{1}\right)$ must be as low as possible, to make the determination of $E_{x 0}$ more accurate. This graph differs from the probability graphs that are in the main report, as this highlights 
the importance of magnitude of impact energy. At Energy level $1\left(E_{1}\right)$, even after five impacts the probability of breakage is less than 0.2 . This suggests that one may probably need hundred attempts to get breakage. At $E_{2}$ and $E_{1}$ each impact contributes significantly to raising the breakage probability, and only a few impacts are required to reach the probability of 1 . One can extrapolate to the right to find the lowest energy that ensures $100 \%$ breakage probability with one impact. However, the main purpose of this graph is to establish $E_{x 0}$ and from the extrapolations of the lines convergence at point on the $X$ axis, giving a value of $E_{x 0}$ to be $0.9 \mathrm{~J}$.

\section{Appendix B}

Suggestion of how drop weight test can be combined with DEM to predict comminution.

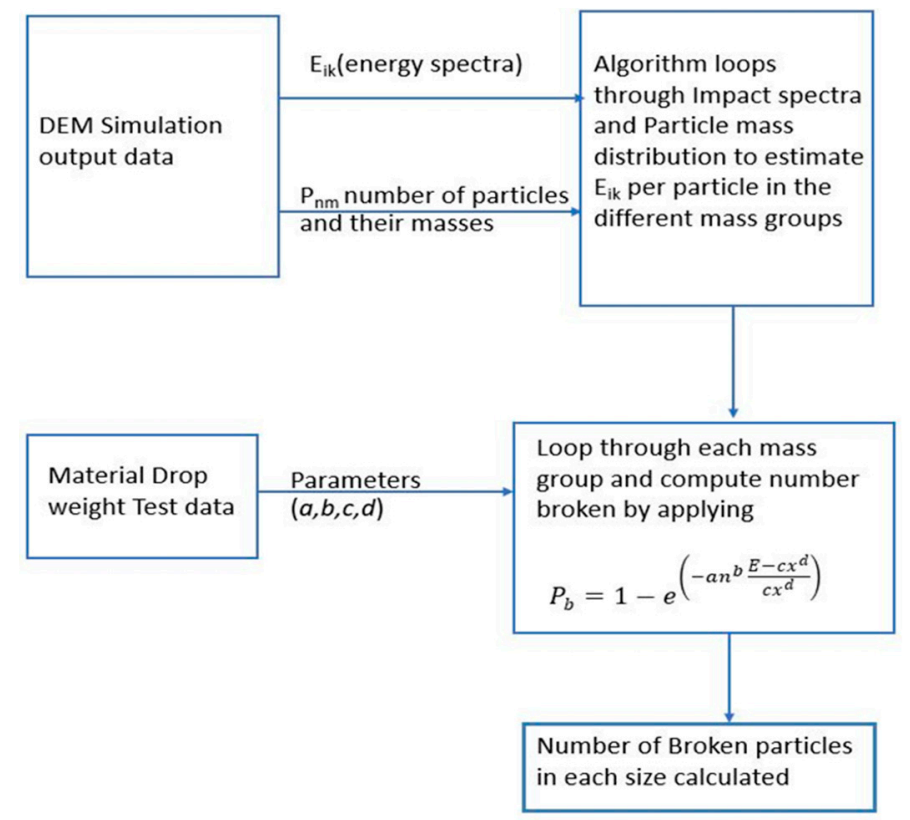

Figure A2. Algorithm that applies drop weight test and DEM simulation data to calculate milling rate.

\section{References}

1. Delboni, H.; Morell, S. A Load-Interactive Model for predicting the performance of autogenous and semi-autogenous mills. Kona Powder Technol. 2002, 20, 208-220. [CrossRef]

2. Von Rittinger, P.R. Lehrbuch der Aufbereitungs Kunde; Ernst and Korn: Berlin, Germany, 1867.

3. Kick, F. Des Gesetz der Proportionalem Widerstnad und Seine Anwendung; Felix: Leipzig, Germany, 1885.

4. Bond, F.C. The third theory of comminution. Trans. AIME 1952, 193, 484-494.

5. Griffith, A. The phenomena of rupture and flow in solids. Phil. Trans. R. Soc. 1921, 221, 163.

6. Rumpf, H. Physical aspect of comminution and a new formulation of a law of comminution. Powder Technol. 1973, 7, 145-159. [CrossRef]

7. Narayanan, S.S. Single particle breakage tests: A review of principles and applications to comminution modelling. Bull Proc. Austr. Inst. Min. Metall. 1986, 291, 49-58.

8. Leung, K. An Energy Based Ore Specific Model for Autogeneous and Semiautogenous Grinding. Ph.D. Thesis, University of Queensland, St Lucia, Australia, 1987.

9. Shi, F.; Kojovic, T.; Larbi-Bram, S.; Manlapig, E. Development of a rapid particle breakage characterisation device-The JKRBT. Miner. Eng. 2009, 22, 602-612. [CrossRef]

10. Bwalya, M.M.; Moys, M.H.; Hinde, A. The use of the DEM and fracture mechanics to improve grinding rate prediction. Miner. Eng. 2001, 14, 565-573. [CrossRef]

11. Weichert, R. Fracture physics in comminution. In Proceedings of the 7th European Symposium Comminution, Ljubljana, Slovenia, 12-14 June 1990; pp. 3-20.

12. Peukert, W.; Vogel, L. Breakage behaviour of different materials-Construction of a master curve for the breakage probability. Powder Technol. 2003, 129, 101-110.

13. Vogel, L.; Peukert, W. Determination of material properties relevant to grinding by practicable labscale milling tests. Int. J. Miner. Process. 2004, 74S, S329-S338. [CrossRef] 
14. Morrison, R.D.; Shi, F.N.; Whyte, R. Modelling of incremental rock breakage by impact: For use in DEM models. Miner. Eng. 2007, 20, 303-309. [CrossRef]

15. Bwalya, M.M. Using the Discrete Element Method to Guide the Modelling of Semi and Fully Autogenous Milling. Ph.D. Thesis, University of Witwatersrand, Johannesburg, South Africa, 2005.

16. Bwalya, M.M.; Moys, M.H. The Use of DEM in Predicting Grinding Rate. In Proceedings of the XXII International Mineral Processing Congress, Cape Town, South Africa, 29 September-3 October 2003; pp. 1612-1617.

17. King, R.P.; Bourgeois, F. Measurement of fracture energy during single-particle fracture. Miner. Eng. 1993, 6, 353-367. [CrossRef]

18. Tavares, L.M.; King, R.P. Modeling of particle fracture by repeated impacts using continuum damage mechanics. Powder Technol. 2002, 123, 138-146. [CrossRef]

19. Tavares, L.M.; Carvalho, R. Modelling breakage rates of coarse materials in ball mills. Miner. Eng. 2009, 22, 650-659. [CrossRef]

20. Genc, O.; Ergun, L.; Benzer, H. Single particle impact breakage characterization of materials by drop-weight testing. Physicochem. Probl. Miner. Process. 2004, 38, 241-255.

21. Shi, F. A review of the applications of the JK size-dependent breakage model Part 1: Ore and coal breakage characterization. Int. J. Miner. Process. 2016, 155, 118-129. [CrossRef]

22. Chandramohan, R.; Lane, G.S.; Foggiatto, B.; Bueno, M.P. Reliability of Some Ore Characterization Tests-Ausenco. In Proceedings of the SAG mill conference, Vancouver, BC, Canada, 20-24 September 2015.

23. Hosseinzadeh, H.; Ergun, L. Determination of Breakage Distribution Function of fine chromite ores with Bed Breakage Method. In Proceedings of the XIII International Mineral Processing Symposium, Bodrum, Turkey, 10-12 October 2012.

24. Bonfils, B.; Ballantyne, G.R.; Powell, M.S. Developments in incremental rock breakage testing methodologies and modeling. Int. J. Miner. Process. 2016, 152, 16-25. [CrossRef]

25. Tavares, L.M.; King, R.P. Single-particle fracture during impact loading. Int. J. Miner. Process. 1998, 54, 1-28. [CrossRef]

26. Baumgardt, S.; Buss, B.; May, P.; Schubert, H. On the Comparison of Results in Single Grain Crushing under Different Kinds of Load; XI. IMPC: Cagliari, Italy, 1975.

(C) 2020 by the authors. Licensee MDPI, Basel, Switzerland. This article is an open access article distributed under the terms and conditions of the Creative Commons Attribution (CC BY) license (http://creativecommons.org/licenses/by/4.0/). 